\title{
Cognitive Function, Habitual Gait Speed, and Late-Life Disability in the National Health and Nutrition Examination Survey (NHANES) 1999-2002
}

\author{
Hsu-Ko Kuo a, b Suzanne G. Leveille ${ }^{d}$ Yau-Hua Yu ${ }^{c}$ William P. Milberg ${ }^{e}$ \\ a Division of Gerontology Research, National Health Research Institutes, ${ }^{b}$ Department of Internal Medicine, \\ National Taiwan University Hospital, and ' National Yang-Ming University, Taipei, Taiwan, ROC; \\ ${ }^{\mathrm{d}}$ Department of Medicine, Beth Israel Deaconess Medical Center and Harvard Medical School, Boston, Mass.,

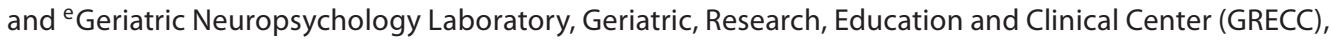 \\ Brockton/West Roxbury Department of Veterans Affairs Medical Center, Boston, Mass., USA
}

\section{Key Words}

Cognition • Cognitive function · Gait speed · Physical function $\cdot$ National Health and Nutrition Examination

\begin{abstract}
Background: Both cognitive function and gait speed are important correlates of disability. However, little is known about the combined effect of cognitive function and gait speed on multiple domains of disability as well as about the role of gait speed in the association between cognitive function and late-life disability. Objective: To investigate (1) how cognition and habitual gait speed are related to late-life disability; (2) the role of habitual gait speed in the cognitiondisability association; and (3) the combined effect of cognitive function and habitual gait speed on late-life disability. Method: Participants ( $>60$ years, $n=2,481$ ) were from the National Health and Nutrition Examination Survey 19992002. Disability in activities of daily living (ADL), instrumental ADL (IADL), leisure and social activities (LSA), and lower extremity mobility (LEM) was obtained by self-report. Cognitive function was measured by a 2-min timed Digit Symbol Substitution Test (DSST), an executive function measure from the Wechsler Adult Intelligence Test. Habitual gait speed was obtained from a 20 -foot timed walk. Multiple lo-
\end{abstract}

gistic regression was used to assess the association between cognitive function and disability. Results: Cognitive function was associated with decreased likelihood for disability in each domain. The odds ratios (ORs) for disability in ADL, IADL, LSA, and LEM for each standard deviation (SD) increase in the DSST score were $0.47(95 \%$ confidence interval $[\mathrm{Cl}]=$ $0.34-0.64), 0.53(95 \% \mathrm{Cl}=0.42-0.67), 0.61$ (95\% Cl = 0.47$0.79)$, and $0.73(95 \% \mathrm{Cl}=0.61-0.86)$, respectively, in the multivariable models. After additional adjustment for habitual gait speed in the cognition-disability relationship, DSST score was no longer a significant correlate for LSA and LEM disability. The strength of the association between DSST score and disability in ADL/IADL was also diminished. The attenuated association between cognition and disability implies that limitation in gait speed likely mediates the association between cognitive function and disability. We found additive effects of cognition and habitual gait speed on latelife disability. The OR of disability in respective domains were lowest among participants with high-DSST score (high executive function) and with high gait speed. In contrast, the OR tended to be highest among participants with low-DSST score (low executive function) and low gait speed. Conclusion: Cognitive function was associated with multiple domains of disability. There was a joint effect of cognitive function and gait speed on late-life disability. This study also

\section{KARGER}

Fax +4161306 1234 E-Mail karger@karger.ch www.karger.com
(C) 2007 S. Karger AG, Basel

0304-324X/07/0532-0102\$23.50/0

Accessible online at:

www.karger.com/ger
Dr. Yau-Hua Yu

11F-2, No. 15, DaZhi Street

Taipei 10463, Taiwan (ROC)

Tel. +886 96608 8355, Fax +8862 85093747

E-Mail yauhuayu@gmail.com 
suggested that habitual gait speed partially mediated the inverse association between cognitive function and late-life disability, providing a mechanistic explanation in the context of disablement process. C Copyright $\odot 2007$ S. Karger AG, Basel

\section{Introduction}

With life expectancy reaching a historic acme, disability and loss of independence have become common features in an aging society [1]. Functional disability represents the interaction of performance ability with an individual's environment, and affects the quality of life of elderly people. Functional disability is associated with the frequent use of health and social services. Disability in older adults has become a major public health concern, receiving increasing attention internationally [2-4]. Operationally, the concept of disability encompasses a number of domains. These include activities of daily living (ADL), instrumental activities of daily living (IADL), social activities, and leisure activities [5].

Because of the prevalence and complexity of this issue it has become increasingly important to understand the predictors and correlates of functional disability in aging adults. Two seemingly independent but important predictors of disability in old age is the presence of declines in cognition, and gait. Cognitive function has been identified as one of the most important correlates of disability. Cross-sectional studies have shown that low cognitive performance was associated with disability in ADL and IADL $[6,7]$. The cross-sectional association was further supported by several prospective studies. For example, Raji et al. [8] found that low Mini-Mental State Examination scores were associated with increased risk of ADL disability over a 7-year period in older Mexican Americans. Dodge et al. [9] also showed that cognitive impairment predicted incident disability in specific ADL-IADL tasks among community-dwelling Japanese elders [9].

Gait speed, a measure of lower-extremity function, is another important predictor of disability. Guralnik et al. [10] found that lower-extremity function, evaluated by tests of gait speed, standing balance, and time to rise from a chair, was inversely associated with mobility and ADL disability after a 4-year period. Shinkai et al. [11], too, demonstrated that gait speed was a good predictor for ADL dependence in a group of Japanese communitydwelling elders. Moreover, gait speed has been suggested to be related to cognitive function as evidenced by several geriatric studies. Waite et al. [12] suggested that par- ticipants with dementia had gait abnormalities characterized by slowing and ataxia. The InCHIANTI study also demonstrated that executive function correlated with gait speed in older persons [13].

An important theoretical model of the pathway to latelife disability was proposed by Nagi [14]. Nagi's construct of disablement consists of four related but distinct categories that represent the causal connection between pathology and actual disability. These are: 'active pathology' (such as stroke), 'impairment' (such as low muscle strength and cognitive impairment), 'functional limitation' (such as slow gait speed), and 'disability'. Critical to the current data is the idea that disability can be operationalized within several different dimensions including: basic ADL, IADL, role activities, social activities and leisure activities [13-15]. Presumably different underlying pathologies may be linked to different dimensions. Although it is becoming clear that cognitive impairment ('impairment') and slow gait speed ('functional limitation') may co-occur with advancing age, and that each of these factors may contribute to disability, little is known about the role of gait speed in the association between cognition and disability. Moreover, the combined effect of cognition and gait speed on different aspects of disability has not been well-examined. Therefore, we hypothesize that habitual gait speed mediates the cognition-disability association and that there is an additive effect of cognition and habitual gait speed on disability and that this will affect more than one dimension of disability. We will investigate the study hypotheses by analyzing data from the US National Health and Nutrition Examination Survey (NHANES) 1999-2002.

\section{Methods}

\section{Study Design and Population}

The NHANES is a population-based survey designed to collect information on the health and nutrition of the US household population. The NHANES used a stratified, and cluster sampling design to obtain a representative sample of the non-institutionalized civilian US population. Beginning in 1999, the NHANES became a continuous, annual survey rather than the periodic survey that it had been in the past. The survey data are released every 2 years. Detailed Survey Operations Manuals, Consent Documents, and Brochures of the NHANES 1999-2002 are available in the NHANES website [16, 17].

Cognitive functioning was assessed in the NHANES participants aged 60 years and older using the Digit Symbol Substitution Test (DSST). Among the 3,342 participants who could be tested in a quiet place with minimal distractions, 77 refused the sample exercise of DSST. Another 206 potential participants were unable to be tested on the sample DSST because of severe cognitive limi- 


\begin{tabular}{|c|c|}
\hline Domains & Components \\
\hline Activities of daily living & $\begin{array}{l}\text { Eating difficulty } \\
\text { Dressing yourself difficulty } \\
\text { Walking between rooms on same floor difficulty } \\
\text { Getting in and out of bed difficulty }\end{array}$ \\
\hline Instrumental activities of daily living & $\begin{array}{l}\text { Managing money difficulty } \\
\text { House chore difficulty } \\
\text { Preparing meals difficulty }\end{array}$ \\
\hline Leisure and social activities & $\begin{array}{l}\text { Going out to movies and events difficulty } \\
\text { Attending social event difficulty } \\
\text { Leisure activity at home difficulty }\end{array}$ \\
\hline Lower extremity mobility & $\begin{array}{l}\text { Walking for a quarter mile difficulty } \\
\text { Walking up ten steps difficulty }\end{array}$ \\
\hline \multicolumn{2}{|c|}{$\begin{array}{l}\text { * Participants aged } 60 \text { and older were asked } 19 \text { questions in the Physical Functioning } \\
\text { Questionnaire. The remaining } 7 \text { questions, without specifically addressing the above } \\
\text { disability domains, were not included in the analyses. These } 7 \text { questions were (1) stoop- } \\
\text { ing, crouching, kneeling difficulty; (2) lifting or carrying difficulty; (3) standing up from } \\
\text { armless chair difficulty; (4) standing for long periods difficulty; (5) sitting for long pe- } \\
\text { riods difficulty; (6) reaching up over head difficulty; and (7) grasp/holding small objects } \\
\text { difficulty. }\end{array}$} \\
\hline
\end{tabular}

tations (e.g. inability to understand the instructions), physical limitations (e.g. arthritis or hand injury etc.), or other reasons related to testing conditions (e.g. no flat surface for writing). Of the 3,059 participants who successfully completed the sample DSST, 19 never worked on the 2-min timed DSST while 65 started the 2-min DSST but did not complete the test, leaving 2,975 participants who worked for the entire 2-min duration. All of the 2,975 participants finished the Physical Functioning Questionnaire (PFQ) to assess the level of disability in performing various tasks without using any special equipment. Of these, 494 were missing values in timed 20 -foot walk test because of participants' absence for gait speed evaluation (263 participants), being unable to walk alone without holding onto someone (227 participants), or other reasons not specified (4 participants). Those with non-missing values tended to perform better in the DSST (correct answers 42 vs. 34 ), be younger ( 71.0 vs. 74.7 years), be more male (49.4 vs. $43.2 \%)$, and be less disabled in all disability domains. No differences were noted in body mass index (BMI) or race/ethnicity. Therefore, the analytic sample was composed of 2,481 participants who completed the DSST, timed walk test, as well as PFQ to ascertain self-reported disability.

\section{Cognitive Function}

DSST, the cognitive test in the NHANES, was administered during the household interview. The DSST, a component of the Wechsler Adult Intelligence Test [18] and a test of visuospatial and motor speed-of-processing, has a considerable executive function component and is frequently used as a sensitive measure of frontal lobe executive functions $[19,20]$. Participants were asked to copy symbols that were paired with numbers within $2 \mathrm{~min}$. Following the standard scoring method, one point is given for each correctly drawn symbol. The maximum score is 133 .

\section{Disability}

The PFQ was designed to assess levels of dependence in performing various tasks. Twelve questions, selected from the original 19 questions, were classified into four disability domains: ADL, IADL, leisure and social activities (LSA), and lower extremity mobility (LEM) (table 1). A participant's answer to a given question was coded as 'no difficulty', 'some difficulty', 'much difficulty', or 'unable to do'. Disability was defined if a person reported much difficulty or unable to perform any activities within a given domain.

\section{Habitual Gait Speed}

Habitual gait speed was measured in the Medical Examination Center (MEC) of the NHANES according to a standardized protocol. A 20 feet long test tract area was set up in a corridor of the MEC. The 20-foot walk was timed using a hand-held stopwatch. Habitual gait speed was selected as the measure of walking function because it predicted subsequent disability $[10,11]$. The $20-$ foot timed walk test was performed at the participant's usual pace. Use of a walker or cane was allowed if needed. Habitual gait speed was calculated as walking distance $(20 \mathrm{feet}=6.15 \mathrm{~m})$ divided by time (s).

\section{Adjusted Covariates}

Age, gender, race, educational level, and smoking status were obtained from self-report. Diabetes was defined by a self-report doctor's diagnosis, the presence of a random glucose level $>200 \mathrm{mg} / \mathrm{dl}$, or the use of diabetic medications (insulin and/or oral hypoglycemic agents). Three and sometimes four blood pressure (BP) determinations were taken using a mercury sphygmomanometer by a physician. BP was measured in the right arm unless otherwise specified. Averaged systolic and diastolic BPs 
were obtained. The presence of hypertension was defined by a self-report of the doctor's diagnosis, use of anti-hypertensive medications, or averaged $\mathrm{BP}>140 / 90 \mathrm{~mm} \mathrm{Hg}$. BMI, calculated as weight $(\mathrm{kg})$ divided by height square $\left(\mathrm{m}^{2}\right)$, was categorized according to the National Institutes of Health standards: $<18.5$ underweight; 18.5-24.9 normal weight; 25.0-29.9 overweight; and $>30$ obese [21]. Co-morbidities including stroke, myocardial infarction, coronary heart disease, congestive heart failure, angina, chronic bronchitis, emphysema, and arthritis were ascertained by self-report. Heart disease was defined if participants had myocardial infarction, coronary heart disease, congestive heart failure, or angina; while chronic obstructive pulmonary disease (COPD) if participants had chronic bronchitis or emphysema. Health perception was ascertained by the questionnaire 'How would you say your health in general is?' and was categorized to excellent, very good, good, fair, or poor. The need of wearing glasses to read was recorded. Alcohol intake was determined by asking 'In any 1 year, have you had at least 12 drinks of any type of alcohol beverage?' and was dichotomized. Plasma homocysteine was measured by an automated fluorescence polarization immunoassay method. Nutritional markers including serum vitamin $\mathrm{B}_{12}$ and folate levels were measured by using the Bio-Rad Laboratories Folate/vitamin $\mathrm{B}_{12}$ radioassay kit. C-reactive protein (CRP) was quantified by utilizing latex-enhanced nephelometry.

\section{Analysis}

DSST scores were normally distributed. Therefore, individual standard deviation (SD) score for DSST were obtained from the formula $\left(\mathrm{X}_{\mathrm{i}}-\mathrm{X}_{\mathrm{m}}\right) / \mathrm{SD}$, where $\mathrm{X}_{\mathrm{i}}$ is the individual value of the DSST score in the individual participant, $\mathrm{X}_{\mathrm{m}}$ the mean values of the DSST score in the study cohort, and SD the standard deviation of the DSST score in the study cohort. The SD scores of DSST were related to multiple domains of disability by using multiple logistic regression. We used an extended-model approach for covariates adjustments: Model 1 = demographics, educational level, BMI categories, and use of eye glasses for reading; Model $2=$ Model $1+$ co-morbidities (hypertension, diabetes, stroke, heart disease, COPD, and arthritis); Model $3=$ Model $2+$ health behaviors (smoking status and alcohol intake) + health perception + nutritional and inflammatory markers (folate, vitamin $\mathrm{B}_{12}$, homocysteine, and CRP); while Model $4=$ Model $3+$ habitual gait speed. The odds ratio (OR) for disability was obtained for each SD increase in the DSST scores. In addition, we categorized DSST scores into quartiles with the lowest quartile as the reference group.

To evaluate joint effects of cognition and habitual gait speed on disability, study participants were re-classified in one of four groups based upon whether their DSST scores and habitual gait speed were above or below the respective study medians (DSST median $=42$, habitual gait speed median $=0.943 \mathrm{~m} / \mathrm{s})$ : highDSST/high-speed (792 participants), high-DSST/low-speed (408 participants), low-DSST/high-speed (448 participants), and lowDSST/low-speed (833 participants). The ORs for disability were obtained using multiple logistic regression with participants in the high-DSST/high-speed as the reference group.

Because the NHANES population weights are only applicable to analyses using the entire population and we limited our analyses to a special subset of participants, we did not use the NHANES population weights for the purposes of this study. Data analyses were performed using STATA 8.0 software (STATA Corporation, College Station, Tex., USA).

Cognitive Function, Gait Speed, and Disability in the NHANES

\section{Results}

\section{Characteristics of Study Population}

Baseline characteristics of the group as a whole $(\mathrm{n}=$ 2,481 , mean age $=71.0$ years) and by quartiles of DSST were summarized (table 2). More than half of the study sample was non-Hispanic White $(61.1 \%)$ and the mean BMI was $28.2 \mathrm{~kg} / \mathrm{m}^{2}$. In the context of chronic conditions, $69.0 \%$ of the participants showed evidence of hypertension, $17.0 \%$ diabetes, $5.9 \%$ stroke, $19.3 \%$ heart diseases, $9.8 \%$ COPD, and $46.8 \%$ arthritis.

Participants in the upper quartiles of DSST scores tended to be female, younger, and non-Hispanic white. Participants with high-DSST score tended to receive higher education, walk faster, have lower prevalence of hypertension, diabetes mellitus, stroke, heart disease, and disability, as well as have lower levels of homocysteine and CRP.

\section{Habitual Gait Speed in the Association between Cognitive Function and Disability}

We observed a positive association between cognitive function and gait speed. There was a small, yet statistically significant increase in habitual gait speed $(0.055 \mathrm{~m} / \mathrm{s}, \mathrm{p}<0.001$; effect size $=0.22)$ for each SD increase in the DSST scores after adjustment for demographics, educational level, BMI categories, use of eye glasses, co-morbidities, smoking status, alcohol intake, health perception, as well as markers of nutrition and inflammation. Gait speed was inversely associated with disability. At the same level of adjustment, the ORs for disability in ADL, IADL, LSA, and LEM for each $0.1 \mathrm{~m} / \mathrm{s}$ increase in habitual gait speed were 0.62 (95\% confidence interval $[\mathrm{CI}]=0.55-0.69), 0.65(95 \% \mathrm{CI}=0.60-0.70), 0.61$ (95\% CI $=0.55-0.67)$, and 0.66 (95\% CI $=0.62-0.71)$, respectively.

Higher scores of DSST were associated with decreased odds of late-life disability after adjustment for demographics, education levels, use of eye glasses, and BMI categories (Model 1, table 3). After additionally controlling for covariates including co-morbidities, smoking status, alcohol intake, health perception, as well as nutritional and inflammatory markers (Models 2 and 3 , table 3 ), the negative association between cognitive function and disability was mildly attenuated and remained highly significant. In Model 4, where habitual gait speed was introduced as a covariate in the cognition-disability interrelationships, DSST score was no longer a significant predictor for disability in LSA and LEM. The strength of the association between DSST 
Table 2. Characteristics of study population according to performance of digit symbol substitution test $(\mathrm{n}=2,481)$

\begin{tabular}{|c|c|c|c|c|c|c|}
\hline \multirow[t]{2}{*}{ Characteristics } & \multicolumn{6}{|c|}{ Quartiles of Digit Symbol Substitution Test scores } \\
\hline & $\begin{array}{l}0-30 \\
(n=661)\end{array}$ & $\begin{array}{l}31-42 \\
(\mathrm{n}=620)\end{array}$ & $\begin{array}{l}43-55 \\
(n=596)\end{array}$ & $\begin{array}{l}56-117 \\
(\mathrm{n}=604)\end{array}$ & Total & $\mathrm{p}$ value \\
\hline \multicolumn{7}{|l|}{ Continuous variables ${ }^{\mathrm{a}}$} \\
\hline Age, year & $72.8(8.1)$ & $72.4(7.8)$ & $70.9(7.4)$ & $67.7(6.4)$ & $71.0(7.7)$ & $<0.001$ \\
\hline Body mass index, $\mathrm{kg} / \mathrm{m}^{2}$ & $28.2(5.4)$ & $27.9(5.6)$ & $28.4(5.2)$ & $28.3(5.4)$ & $28.2(5.4)$ & 0.332 \\
\hline Habitual gait speed, $\mathrm{m} / \mathrm{s}$ & $0.798(0.239)$ & $0.891(0.224)$ & $0.985(0.221)$ & $1.080(0.241)$ & $0.935(0.255)$ & $<0.001$ \\
\hline Homocysteine, $\mu \mathrm{mol} / \mathrm{l}^{\mathrm{b}}$ & $9.87(4.84)$ & $9.81(4.11)$ & $9.01(3.45)$ & $8.44(3.22)$ & $9.24(3.91)$ & $<0.001$ \\
\hline Folate, $\mathrm{ng} / \mathrm{ml}^{\mathrm{b}}$ & $14.7(10.0)$ & $15.8(11.2)$ & $16.2(11.8)$ & $18.5(13.0)$ & $16.2(11.9)$ & $<0.001$ \\
\hline Vitamin $\mathrm{B}_{12}, \mathrm{pg} / \mathrm{ml}^{\mathrm{b}}$ & $487(320)$ & $469(287)$ & $479(269)$ & $484(288)$ & $479(289)$ & 0.807 \\
\hline C-reactive protein, $\mathrm{mg} / \mathrm{dl}^{\mathrm{b}}$ & $0.33(0.51)$ & $0.26(0.42)$ & $0.28(0.40)$ & $0.25(0.43)$ & $0.28(0.44)$ & $<0.001$ \\
\hline \multicolumn{7}{|l|}{ Categorical variables ${ }^{\mathrm{c}}$} \\
\hline Female & $306(46.3)$ & $288(46.5)$ & $303(50.8)$ & $360(59.6)$ & $1,257(50.7)$ & $<0.001$ \\
\hline Non-Hispanic white & $237(35.8)$ & $375(60.5)$ & $422(70.8)$ & $483(80.0)$ & $1,517(61.1)$ & $<0.001$ \\
\hline Education higher than high school & $69(10.4)$ & $187(30.2)$ & $282(47.3)$ & $363(60.1)$ & $901(36.3)$ & $<0.001$ \\
\hline Current smoker & $94(14.2)$ & $92(14.8)$ & $79(13.3)$ & $67(11.1)$ & $332(13.4)$ & 0.233 \\
\hline Alcohol intake $>12$ drinks per year & $351(53.1)$ & $354(57.1)$ & $373(62.6)$ & $415(68.7)$ & $1,493(60.2)$ & $<0.001$ \\
\hline Hypertension & $491(74.3)$ & $442(71.3)$ & $410(68.8)$ & $368(60.9)$ & $1,711(69.0)$ & $<0.001$ \\
\hline Diabetes mellitus & $162(24.5)$ & $125(20.2)$ & $75(12.6)$ & $60(9.9)$ & $422(17.0)$ & $<0.001$ \\
\hline Stroke & $68(10.3)$ & $46(7.4)$ & $19(3.2)$ & $13(2.2)$ & $146(5.9)$ & $<0.001$ \\
\hline Heart diseases $^{\mathrm{d}}$ & $147(22.2)$ & $154(24.8)$ & $97(16.3)$ & $81(13.4)$ & $479(19.3)$ & $<0.001$ \\
\hline Chronic obstructive pulmonary diseases ${ }^{\mathrm{d}}$ & $65(9.8)$ & $74(11.9)$ & $55(9.2)$ & $50(8.3)$ & $244(9.8)$ & 0.173 \\
\hline Arthritis & $316(47.8)$ & $302(48.7)$ & $278(46.6)$ & $265(43.9)$ & $1,161(46.8)$ & 0.650 \\
\hline \multicolumn{7}{|l|}{ Self-reported disability ${ }^{\mathrm{e}}$} \\
\hline Activities of daily living & $52(7.9)$ & $32(5.2)$ & $13(2.2)$ & $6(1.0)$ & $103(4.2)$ & $<0.001$ \\
\hline Instrumental activities of daily living & $116(17.6)$ & $56(9.0)$ & $27(4.5)$ & $19(3.2)$ & $218(8.8)$ & $<0.001$ \\
\hline Leisure and social activities & $77(11.7)$ & $50(8.1)$ & $17(2.9)$ & $15(2.5)$ & $159(6.4)$ & $<0.001$ \\
\hline Lower extremity mobility & $175(26.5)$ & $140(22.6)$ & $73(12.3)$ & $55(9.1)$ & 443 (17.9) & $<0.001$ \\
\hline $\begin{array}{l}\text { a Values in the continuous variables we } \\
\text { b Values were expressed as median (int } \\
{ }^{c} \text { Values in the categorical variables we } \\
\text { d Heart diseases include myocardial in } \\
\text { tive pulmonary diseases include chronic b } \\
\text { e Disability in a specific functional dor } \\
\text { tivities within a given disability domain. } \\
\text { Uni-variable regression was used to de } \\
\text { it Symbol Substitution Test scores; while }\end{array}$ & $\begin{array}{l}\text { expressed as } n \\
\text { ction, angina, } \\
\text { nchitis or emp } \\
\text { in was defined } \\
\text { mine significa } \\
\text {-square test w }\end{array}$ & $\begin{array}{l}\text { ean (standard } \\
\text { due to right ske } \\
\text { mber (\%). } \\
\text { oronary heart } \\
\text { ysema. } \\
\text { f a person repor } \\
\text { ce difference of }\end{array}$ & $\begin{array}{l}\text { sease, or cong } \\
\text { ed much diffi } \\
\text { elected contir }\end{array}$ & $\begin{array}{l}\text { ive heart failu } \\
\text { ty or unable } t \\
\text { us variables }\end{array}$ & $\begin{array}{l}\text { perform one o } \\
\text { phile chron }\end{array}$ & $\begin{array}{l}\text { obstruc- } \\
\text { more ac- } \\
\text { the Dig- }\end{array}$ \\
\hline
\end{tabular}

score and disability in ADL and IADL had weakened but persisted to be significant. The results were unchanged using a quartile-based (of DSST scores) approach.

\section{Joint Effect of Cognitive Performance and Habitual Gait Speed on Disability}

We computed the ORs for disability in analyses where study participants were stratified into four groups: highDSST/high-speed (reference), high-DSST/low-speed, low-DSST/high-speed, and low-DSST/low-speed. We found additive effects of cognition and habitual gait speed on late-life disability. The odds of disability in respective domains were lowest among participants with high-DSST score and high gait speed and were highest among participants with low-DSST score and low gait speed (fig. 1). The ORs for disability in ADL, IADL, LSA, and LEM were 16.85 (95\% CI $=4.82-58.80, \mathrm{p}<0.001), 10.34(95 \%$ $\mathrm{CI}=4.88-21.92, \mathrm{p}<0.001), 8.12(95 \% \mathrm{CI}=3.46-19.04$, $\mathrm{p}<0.001)$, and 4.45 (95\% CI $=2.88-6.88, \mathrm{p}<0.001)$, respectively, comparing participants with low-DSST/lowspeed vs. high-DSST/high-speed. 
Table 3. Association between cognitive function and late-life disability

\begin{tabular}{|c|c|c|c|c|c|c|c|c|c|}
\hline \multirow[t]{3}{*}{ Models $^{\mathrm{a}}$} & & \multicolumn{8}{|c|}{ Models with Digit Symbol Substitution Test performance (correct numbers) as a continuous variable } \\
\hline & & \multicolumn{2}{|l|}{ ADL disability } & \multicolumn{2}{|l|}{ IADL disability } & \multicolumn{2}{|l|}{ LSA disability } & \multicolumn{2}{|l|}{ LEM disability } \\
\hline & & $\mathrm{OR}^{\mathrm{b}}(95 \% \mathrm{CI})$ & $\mathrm{p}$ value & $\mathrm{OR}^{\mathrm{b}}(95 \% \mathrm{CI})$ & $\mathrm{p}$ value & $\mathrm{OR}^{\mathrm{b}}(95 \% \mathrm{CI})$ & $\mathrm{p}$ value & $\mathrm{OR}^{\mathrm{b}}(95 \% \mathrm{CI})$ & $\mathrm{p}$ value \\
\hline 1 & & $0.45(0.34-0.60)$ & $<0.001$ & $0.46(0.38-0.56)$ & $<0.001$ & $0.52(0.41-0.65)$ & $<0.001$ & $0.61(0.53-0.71)$ & $<0.001$ \\
\hline 2 & & $0.45(0.34-0.61)$ & $<0.001$ & $0.47(0.38-0.58)$ & $<0.001$ & $0.54(0.42-0.68)$ & $<0.001$ & $0.63(0.54-0.74)$ & $<0.001$ \\
\hline 3 & & $0.47(0.34-0.64)$ & $<0.001$ & $0.53(0.42-0.67)$ & $<0.001$ & $0.61(0.47-0.79)$ & $<0.001$ & $0.73(0.61-0.86)$ & $<0.001$ \\
\hline 4 & & $0.59(0.42-0.83)$ & 0.002 & $0.66(0.52-0.83)$ & 0.001 & $0.79(0.60-1.05)$ & 0.101 & $0.90(0.75-1.08)$ & 0.248 \\
\hline \multirow[t]{3}{*}{ Models $^{\mathrm{a}}$} & \multirow{3}{*}{$\begin{array}{l}\text { Quartiles } \\
\text { com- } \\
\text { parison }\end{array}$} & \multicolumn{8}{|c|}{ Models with Digit Symbol Substitution Test performance (correct numbers) by increasing quartiles } \\
\hline & & \multicolumn{2}{|l|}{ ADL disability } & \multicolumn{2}{|l|}{ IADL disability } & \multicolumn{2}{|l|}{ LSA disability } & \multicolumn{2}{|l|}{ LEM disability } \\
\hline & & $\mathrm{OR}^{\mathrm{c}}(95 \% \mathrm{CI})$ & $\mathrm{p}$ for trend & $\mathrm{OR}^{\mathrm{c}}(95 \% \mathrm{CI})$ & $\mathrm{p}$ for trend & $\mathrm{OR}^{\mathrm{c}}(95 \% \mathrm{CI})$ & $\mathrm{p}$ for trend & $\mathrm{OR}^{\mathrm{c}}(95 \% \mathrm{CI})$ & $\mathrm{p}$ for trend \\
\hline \multirow[t]{3}{*}{1} & Q2 vs. Q1 & $0.65(0.40-1.07)$ & $<0.001$ & $0.46(0.32-0.66)$ & $<0.001$ & $0.70(0.46-1.05)$ & $<0.001$ & $0.83(0.63-1.10)$ & $<0.001$ \\
\hline & Q3 vs. Q1 & $0.26(0.13-0.53)$ & & $0.22(0.13-0.35)$ & & $0.25(0.14-0.45)$ & & $0.40(0.28-0.57)$ & \\
\hline & Q4 vs. Q1 & $0.12(0.04-0.31)$ & & $0.15(0.08-0.28)$ & & $0.24(0.12-0.48)$ & & $0.30(0.20-0.45)$ & \\
\hline \multirow[t]{3}{*}{2} & Q2 vs. Q1 & $0.65(0.39-1.07)$ & $<0.001$ & $0.44(0.30-0.64)$ & $<0.001$ & $0.69(0.45-1.06)$ & $<0.001$ & $0.80(0.59-1.07)$ & $<0.001$ \\
\hline & Q3 vs. Q1 & $0.28(0.14-0.56)$ & & $0.24(0.14-0.39)$ & & $0.28(0.15-0.52)$ & & $0.43(0.30-0.61)$ & \\
\hline & Q4 vs. Q1 & $0.12(0.05-0.33)$ & & $0.17(0.09-0.31)$ & & $0.28(0.14-0.56)$ & & $0.33(0.22-0.51)$ & \\
\hline \multirow[t]{3}{*}{3} & Q2 vs. Q1 & $0.57(0.33-0.99)$ & $<0.001$ & $0.46(0.31-0.69)$ & $<0.001$ & $0.69(0.44-1.10)$ & 0.001 & $0.85(0.61-1.18)$ & $<0.001$ \\
\hline & Q3 vs. Q1 & $0.28(0.13-0.60)$ & & $0.29(0.17-0.48)$ & & $0.35(0.18-0.65)$ & & $0.53(0.35-0.78)$ & \\
\hline & Q4 vs. Q1 & $0.13(0.04-0.40)$ & & $0.25(0.13-0.47)$ & & $0.40(0.19-0.85)$ & & $0.49(0.31-0.78)$ & \\
\hline \multirow[t]{3}{*}{4} & Q2 vs. Q1 & $0.74(0.41-1.33)$ & 0.007 & $0.57(0.37-0.87)$ & 0.001 & $0.95(0.58-1.55)$ & 0.221 & $1.07(0.76-1.51)$ & 0.265 \\
\hline & Q3 vs. Q1 & $0.47(0.21-1.02)$ & & $0.42(0.24-0.73)$ & & $0.56(0.29-1.10)$ & & $0.79(0.52-1.20)$ & \\
\hline & Q4 vs. Q1 & $0.25(0.08-0.76)$ & & $0.42(0.22-0.82)$ & & $0.78(0.35-1.70)$ & & $0.82(0.50-1.34)$ & \\
\hline
\end{tabular}

a Adjusted covariates: Model 1 = age, sex, race, educational level, body mass index category, and use of eye glasses for reading; Model $2=$ Model $1+$ co-morbidities (hypertension, diabetes, stroke, heart diseases, COPD, and arthritis); Model $3=$ Model $2+$ health behaviors (smoking status and alcohol consumption) + health perception + nutritional and inflammatory markers (folate, vitamin $\mathrm{B}_{12}$, homocysteine, and C-reactive protein); Model $4=\mathrm{Mod}-$ el $3+$ habitual gait speed.

${ }^{\mathrm{b}}$ ORs (odds ratios) were per increment of one standard deviation in the correct numbers of the Digit Symbol Substitution Test.

${ }^{\mathrm{c}}$ ORs are odds ratios of disability comparing participants in the 2nd, 3rd, or 4th quartiles of the Digit Symbol Substitution Test performance to those in the lowest quartile.

$\mathrm{ADL}=$ Activities of daily living; $\mathrm{CI}=$ confidence interval; $\mathrm{IADL}=$ instrumental activities of daily living; LEM = lower extremity mobility; LSA = leisure and social activities; OR = odds ratio; $\mathrm{Q}=$ quartile.

\section{Discussion}

Our study indicated that cognitive function as measured by DSST was inversely associated with multiple domains of disability as assessed by the PFQ. Specifically, poorer cognitive performance was associated with greater disability. Furthermore, this inverse association appeared to be mediated by habitual gait speed. We also demonstrated a joint effect of cognitive function and habitual gait speed on late-life disability.

Our findings support previous studies investigating the interrelationships between cognitive function, physical function, and disability. For example, the prospective MacArthur Studies of Successful Aging, a 7-year prospective study in high functioning elders, showed that cognitive decline was associated with deterioration in both routine physical tasks (such as walking at nor- mal pace and grip strength) and attention demanding tasks (such as walking at fast pace and tandem stand/ walk) [22]. A recent report further demonstrated that the association between poor cognition and incident ADL disability might partially be mediated through handgrip muscle strength [23]. However, the role of lower extremity function, such as gait speed or leg strength thought to be linked with both cognition and disability, was not investigated. Although a combined effect of physical performance and cognitive status on incident disability has been demonstrated by Gill et al. [24] in another study, they did not evaluate a possible mediating role of physical function in the cognition-disability relationship and they confined the study outcome to ADL disability.

In the context of the theoretical Nagi's disablement process $[5,14,15]$, namely, from 'physical/mental impair- 


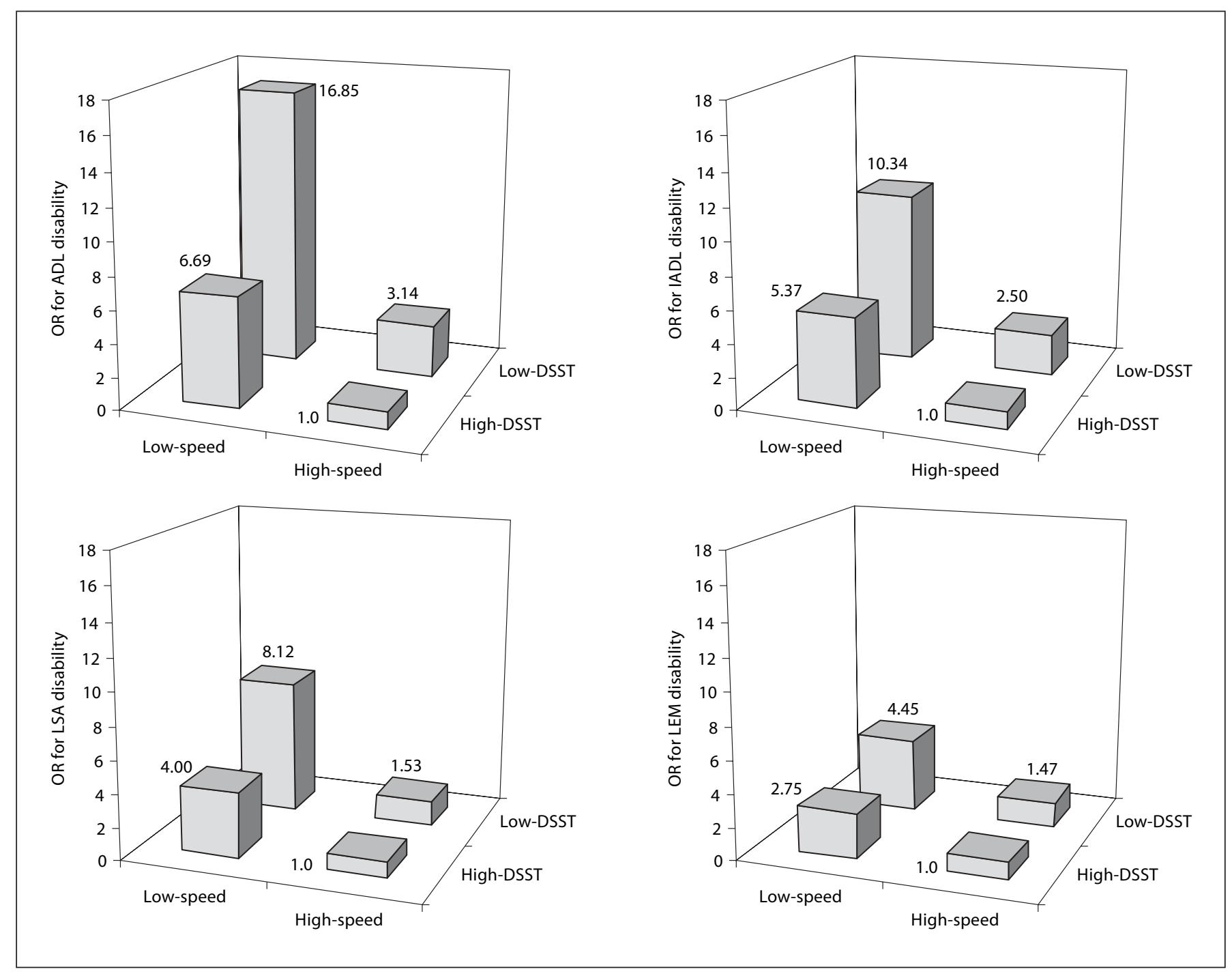

Fig. 1. Study participants were re-classified in one of four groups based on the medians of DSST scores (correct number 42$)$ and habitual gait speed $(0.943 \mathrm{~m} / \mathrm{s})$ : high-DSST/high-speed (792 participants), high-DSST/lowspeed (408 participants), low-DSST/high-speed (448 participants), as well as low-DSST/low-speed (833 participants). The OR for disability in respective domains were obtained with participants in the high-DSST/highspeed as the reference group. The analyses were adjusted for age, sex, race, educational level, BMI category, use of eye glasses for reading, co-morbidities (hypertension, diabetes, stroke, heart diseases, COPD, and arthritis), health behaviors (smoking status and alcohol consumption), health perception, as well as nutritional and inflammatory markers (folate, vitamin $\mathrm{B}_{12}$, homocysteine, and CRP).

ment' to 'functional limitation' and to 'disability', our study provided an excellent opportunity to revisit this model where cognitive function measure (DSST) indicating 'impairment', habitual gait speed 'functional limitation', while self-report status in ADL, IADL, LSA, and LEM 'disability'. We found cognitive function, as assessed by the DSST performance, was associated with multiple domains of disability. The magnitudes of these associations were attenuated after additional adjustment for habitual gait speed, indicating that habitual gait speed partially mediated the cognition-disability association and that gait speed was an intermediate component of the process from cognitive impairment to disability. Geriatric studies with disability as an outcome have typically focused on ADL and/or IADL. In considering the concept of disability, however, varying domains of disability, 
including ADL, IADL, social activities, and leisure activities [14], exist. To the best of our knowledge, this is the first report to describe the association between cognitive function and disability while considering the role of gait speed by using a geographically dispersed and ethnically diverse national representative sample of communitydwelling elders. Additionally, the analysis of disability extended beyond the traditional scope of ADL and IADL, comprehensively covering various disability domains. Our study sheds new light on the disablement process related to cognitive impairment and gait speed, providing data in an important area where data currently do not exist or are not complete.

Our study has several implications. First, cognitive function is an important indicator for functional limitation and disability. Executive functions, assessed by the DSST and referring to higher cognitive processes including multitasking, planning, and organizing, are pivotal for goal-directed behaviors, such as ADL, IADL, LSA, as well as LEM and walking control system. Measurement of cognitive executive function may be useful in identifying and targeting older adults who may require intervention to prevent walking limitation and disability. Second, impairment in cognitive function and gait speed may have an additive effect on the development of late-life disability. Thus, the importance of implementing strategy to prevent decline of both conditions cannot be overemphasized. Regular physical activity including walking exercise, shown to be effective in preventing cognitive decline $[25,26]$ and maintaining walking function [27], seems a reasonable recommendation for older people at risk.
Our study has several limitations that deserve comments. The cross-sectional nature of data does not allow any causal inference. The relationship between cognitive function, gait speed, and disability should be studied prospectively. Secondly, we relied on self-report to ascertain disability status in elderly participants potentially affected by cognitive impairment or even dementia. However, previous studies have demonstrated a good agreement between proxies' assessment and patients' perceptions regarding patients' functional status [28, 29]. Thirdly, in the present study, we were unable to evaluate the role of a possible cerebral 'pathology', such as leukoaraiosis, ventricular enlargement, or reduced cerebral blood flow, which might be the stem of the Nagi's disablement process from 'impairment' (cognitive function) to 'functional limitation' (gait speed) and to 'disability' (various disability domains). The idea warrants further investigation within mechanistic studies specifically designed around disablement concepts.

\section{Conclusion}

In conclusion, cognitive function was associated with multiple domains of disability among the US community-dwelling elders. There was a joint effect of cognitive function and gait speed on disability. This study also suggested that habitual gait speed might partially mediate the cognition-disability association, providing a mechanistic explanation in the context of disablement process.

\section{References}

1 Manton KG, Corder LS, Stallard E: Estimates of change in chronic disability and institutional incidence and prevalence rates in the U.S. elderly population from the 1982, 1984, and 1989 National Long Term Care Survey. J Gerontol 1993;48:S153-166.

2 Bass S, Morris R, Oka M: Public Policy and the Old Age Revolution in Japan. New York, Haworth Press, 1996.

3 Schulte B: Social protection for dependence in old age: the case of Germany; in Eisen R, Sloan F (eds): Long Term Care: Economic Issues and Policy Solutions. Boston, Kluwer Academic, 1996, pp 149-170.
4 Wiener J: Long Term Care Reform: An International Perspective. Health Care Reform: The Will to Change. Paris, Organization for Economic Cooperation and Development, 1996.

5 Jette AM: Disablement outcomes in geriatric rehabilitation. Med Care 1997;35(suppl): JS28-JS37; discussion JS38-JS44.

6 Blaum CS, Ofstedal MB, Liang J: Low cognitive performance, comorbid disease, and task-specific disability: findings from a nationally representative survey. J Gerontol A Biol Sci Med Sci 2002;57:M523-M531.

7 Carlson MC, Fried LP, Xue QL, BandeenRoche K, Zeger SL, Brandt J: Association between executive attention and physical functional performance in community-dwelling older women. J Gerontol B Psychol Sci Soc Sci 1999;54:S262-S270.
$>8$ Raji MA, Al Snih S, Ray LA, Patel KV, Markides KS: Cognitive status and incident disability in older Mexican Americans: findings from the Hispanic established population for the epidemiological study of the elderly. Ethn Dis 2004;14:26-31.

$\checkmark 9$ Dodge HH, Kadowaki T, Hayakawa T, Yamakawa M, Sekikawa A, Ueshima H: Cognitive impairment as a strong predictor of incident disability in specific ADL-IADL tasks among community-dwelling elders: the Azuchi Study. Gerontologist 2005;45:222230 .

10 Guralnik JM, Ferrucci L, Simonsick EM, Salive ME, Wallace RB: Lower-extremity function in persons over the age of 70 years as a predictor of subsequent disability. $\mathrm{N}$ Engl J Med 1995;332:556-561. 
-11 Shinkai S, Watanabe S, Kumagai S, et al: Walking speed as a good predictor for the onset of functional dependence in a Japanese rural community population. Age Ageing 2000;29:441-446.

-12 Waite LM, Broe GA, Creasey H, Grayson D, Edelbrock D, O’Toole B: Neurological signs, aging, and the neurodegenerative syndromes. Arch Neurol 1996;53:498-502.

$>13$ Ble A, Volpato S, Zuliani G, et al: Executive function correlates with walking speed in older persons: the InCHIANTI study. J Am Geriatr Soc 2005;53:410-415.

14 Nagi SZ: An epidemiology of disability among adults in the United States. Milbank Mem Fund Q Health Soc 1976;54:439-467.

$\checkmark 15$ Verbrugge LM, Jette AM: The disablement process. Soc Sci Med 1994;38:1-14.

16 1999-2000 National Health and Nutrition Examination Survey (NHANES). Http:// www.cdc.gov/nchs/about/major/nhanes/ currentnhanes.htm. Bathesda, MD, National Center for Health Statistics.

17 National Health and Nutrition Examination Survey (NHANES): Http://www.cdc.gov/ nchs/about/major/nhanes/current_ nhanes_01_02.htm. Bathesda, MD, National Center for Health Statistics, 2001-2002.
18 Wechsler D: Manual for the Wechsler Adult Intelligence Scale-Revised. New York, The Psychological Corporation, 1981.

19 Vilkki J, Holst P: Mental programming after frontal lobe lesions: results on digit symbol performance with self-selected goals. Cortex 1991;27:203-211.

20 Parkin AJ, Java RI: Deterioration of frontal lobe function in normal aging: influences of fluid intelligence versus perceptual speed. Neuropsychology 1999;13:539-545.

21 National Heart, Lung, and Blood Institute: Obesity Education Initiative: The Evidence Report. Bethesda, MD, Nation Institutes of Health, 1998.

22 Tabbarah M, Crimmins EM, Seeman TE: The relationship between cognitive and physical performance: MacArthur Studies of Successful Aging. J Gerontol A Biol Sci Med Sci 2002;57:M228-M235.

23 Raji MA, Kuo YF, Snih SA, Markides KS, Kristen Peek M, Ottenbacher KJ: Cognitive status, muscle strength, and subsequent disability in older mexican americans. J Am Geriatr Soc 2005;53:1462-1468.
24 Gill TM, Williams CS, Richardson ED, Tinetti ME: Impairments in physical performance and cognitive status as predisposing factors for functional dependence among nondisabled older persons. J Gerontol A Biol Sci Med Sci 1996;51:M283-M288.

25 Weuve J, Kang JH, Manson JE, Breteler MM, Ware JH, Grodstein F: Physical activity, including walking, and cognitive function in older women. JAMA 2004;292:1454-1461.

-26 Abbott RD, White LR, Ross GW, Masaki KH, Curb JD, Petrovitch $\mathrm{H}$ : Walking and dementia in physically capable elderly men. JAMA 2004;292:1447-1453.

-27 Puggaard L, Larsen JB, Stovring H, Jeune B: Maximal oxygen uptake, muscle strength and walking speed in 85-year-old women: effects of increased physical activity. Aging (Milano) 2000;12:180-189.

28 Magaziner J, Simonsick EM, Kashner TM, Hebel JR: Patient-proxy response comparability on measures of patient health and functional status. J Clin Epidemiol 1988;41: 1065-1074.

$>29$ Weinberger M, Samsa GP, Schmader K, Greenberg SM, Carr DB, Wildman DS: Comparing proxy and patients' perceptions of patients' functional status: results from an outpatient geriatric clinic. J Am Geriatr Soc 1992;40:585-588. 